International Journal of Social Sciences and Humanities
Available online at www.sciencescholar.us
Vol. 5 No. 3, December 2021, pages: $232-242$
e-ISSN: 2550-7001, p-ISSN: 2550-701X
https://doi.org/10.53730/ijssh.v5n3.2028

\title{
Problem-Based Learning as A Methodological Strategy in the Teaching-Learning Process
}

\author{
José Bernardo Cobeña Alava a , Liseth Estefania Aguirre Vera ${ }^{b}$, Verónica Flores Tipán ${ }^{c}$, Gissella \\ Valentina Loor Pinargote ${ }^{d}$
}

Manuscript submitted: 18 September 2021, Manuscript revised: 09 October 2021, Accepted for publication: 27 November 2021

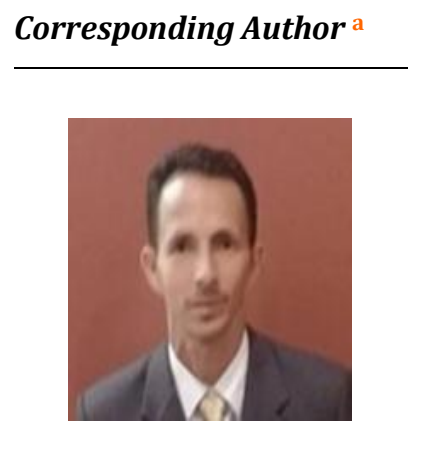

\section{Keywords}

education;

learning;

methodological strategy;

problem-based learning;

teaching;

\begin{abstract}
The educational strategies implemented within the classroom arise from the needs that are presented in the same environment where their academic activities are developed. The teacher has the leading role to strengthen their knowledge. From this point of view, the ABP seeks to develop in students a new learning model that enhances their abilities and promotes the development of their abilities. The objective of the research was to analyze the incidence of Problem-Based Learning in teachers and students of Basic General Education, surveys were applied to teachers, as a source of primary information, in the same way, the deductive, bibliographic, descriptive, and historical method Through this methodological process, it was possible to develop more feasibly the research with the study of several authors, with the collection and analysis of the information it was obtained as a result that the teachers through the contextualization of their practice focused on the use of methodological strategies allow solving situations from simple to complex case study, as well as ensuring that the student encourages different ways of learning from their own experiences, to improve classroom practice with the application of this strategy seeking integration active from its participation and context where it unfolds.
\end{abstract}

International Journal of Social Sciences and Humanities (C) 2021. This is an open access article under the CC BY-NC-ND license (https://creativecommons.org/licenses/by-nc-nd/4.0/).

\section{Contents}

Abstract

1 Introduction

Materials and Methods

3 Results and Discussions

4 Conclusion

Pontificia Universidad Católica del Ecuador, Manabí, Portoviejo, Ecuador

Pontificia Universidad Católica del Ecuador, Manabí, Portoviejo, Ecuador

Pontificia Universidad Católica del Ecuador, Manabí, Portoviejo, Ecuador

Pontificia Universidad Católica del Ecuador, Manabí, Portoviejo, Ecuador 


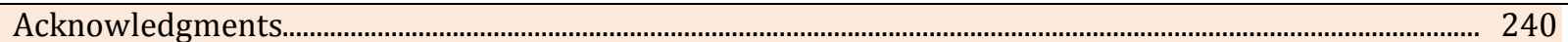

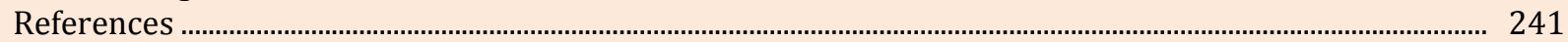

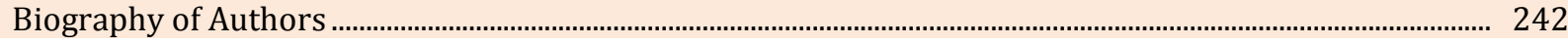

\section{Introduction}

We live in a fast-paced world, where technology is increasingly gaining ground in our daily work, and this also involves the educational processes that have to keep up with these advances, currently, teachers and students see how social life varies in a different way, where family, social, political, economic problems, etc., play a preponderant role in the development of humanity, it is here, in this problem, where the teacher-student must face these situations with a different dynamic where the critical and differentiated attitude is revealed to try to find alternatives for changes and solutions to these problems from a different perspective. constructivist approach.

The (ABP) is focused on the search for new knowledge and the development of new skills and attitudes typical of a researcher and generates a critical judgment that allows both the teacher and the student to face new challenges in their professional lives. The ABP according to González \& del Valle López (2008), they determine it as "a methodological strategy that seeks the active involvement of students to solve problems and thereby acquire new knowledge, becoming a communication channel between teacher, student, and the study problem" (p.15). Starting from this conceptualization, this methodological strategy makes the teachinglearning process a fundamental pillar that allows collaborative work as a determining factor for the acquisition of new knowledge, starting from their experiences (Berkhof et al., 2011; Hallgren \& Olhager, 2006).

On the other hand (Gorghiu et al., 2015), points out that the PBL is "A teaching-learning method whose starting point is a problem that, designed by the teacher, the student has to solve to develop certain previously defined competencies". In this context, the author starts from the teaching-learning method as an active activity that stimulates the student to be critical through questions that are of great interest to them and that are strengthening for the teacher, where they seek to discover new abilities and skills of the student from his own experience (Dewi, 2018). Continuing with this same author, he states that discovering is guided by the teaching staff, who happens to have a role of companion and tutor in the steps that each student takes, to reduce frustration and encourage self-improvement and discovery. And he concludes that with this way of learning the students develop skills such as: problem-solving, decision making, teamwork, argumentation, presentation of information, and attitudes and values (Eisner, 2002; Rots et al., 2007).

The PBL as stated by the various authors is embodied as an innovative teaching method, the same one that within its main characteristics is that the student promotes the development of critical thinking, can seek solutions to problems in a scientific way, has empathy for the search for information and, above all, enhance your skills in communicating information as a research entity. It is necessary for the teacher to be a transport that leads the student to discover the answers to their questions about the why of things, why of the phenomena from a broader perspective, and with answers that validate the student's unknown. Through this strategy, the student becomes the protagonist of their learning and the teacher in the guide, directed to a single purpose, the search for a solution (Vetchinova \& Shishova, 2020).

This educational process leads, in the first place, in students to reflective practice, the same one that allows them to develop multiple capacities such as systemic thinking, critical reflection, and metacognition. Second, to effectively develop the ability to manage knowledge; This allows the student to be able to select and organize information, classify it according to their knowledge, make use of what is relevant to solve problem situations, among other functions. Another advantage that the ABP has in students is that it develops the ability to adapt to social changes, be flexible, proactive, with a greater vision of the projects they face every day and above all, from the same needs of the environment to give a viable solution or alternative solutions to comply with the proposal.

Alava, J. B. C., Vera, L. E. A., Tipán, V. F., \& Pinargote, G. V. L. (2021). Problem-based learning as a methodological strategy in the teaching-learning process. International Journal of Social Sciences and Humanities, 5(3), 232-242. https://doi.org/10.53730/ijssh.v5n3.2028 


\section{Materials and Methods}

The deductive method was used that allowed obtaining information based on the data obtained from the applied technique, in addition to the theories about Problem-Based Learning as a methodological strategy in the teaching-learning process, as well as interpreting through the logical reasoning the significance of the phenomenon to later compare its validity within the research, to strengthen the research process the bibliographic was used, allowing a reliable review of the literature in addition to collecting and organizing critically evaluating the information, the descriptive one for the analysis of the different situations and manifestations. And to finish, the documentary research of different authors on the issue raised was used. The technique that was applied was the survey directed to teachers of Higher Basic Education of the Fiscal Educative Unit Veintitrés de Octubre, Parroquia, Montecristi Canton, which allowed us to recognize the importance of Problem-Based Learning as a strategy for the solution of student problems (Celik et al., 2011; Alkhasawneh et al., 2008).

\section{Results and Discussions}

The PBL is a methodology applied so that students can develop their knowledge through the elaboration that helps them develop new skills, ways of a researcher, in addition to creating a qualifying judgment that allows both the teacher and for students to face new challenges in their professional life, Figure 1 shows a scheme related to PBL and the roles of the teacher and the student.

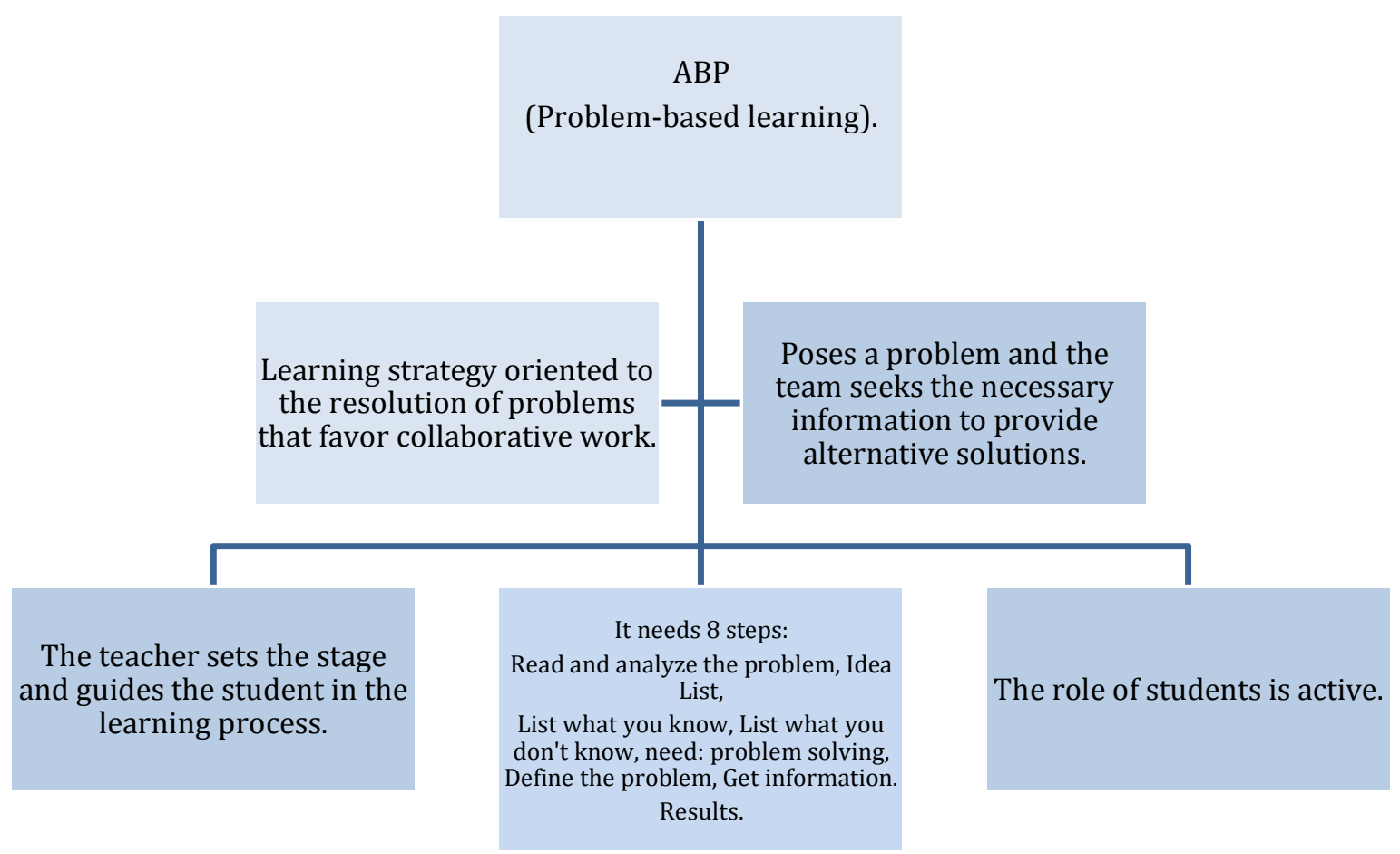

Figure 1. Characteristics of problem-based learning

\section{Learning strategies oriented to problem-solving}

With this methodology, the student assumes a leading role, since he is the one who identifies what he needs to learn to solve the problem posed by the teacher, according to Coila et al., (2019), the PBL is a strategy that 
starts from a problem to generate certain learning in students, through research and analysis processes. The application of this strategy has a high impact on the development of competencies, the achievement of student learning, and the innovation of the teacher's role in the application of strategies to solve a specific problem. It is considered as a didactic technique that promotes effective learning with active methodologies within a scenario such as promoting a positive attitude towards learning, seeking self-autonomy, generating selflearning in the student, promoting responsibility for their learning, developing an effective and creative knowledge base, developing skills for evaluation, criticism and acquire new knowledge (Seufert, 2003; Hedegaard, 2014).

\section{Characteristics of students who seek information}

The importance of learning lies in the student is based on the social commitment and predisposition of the facts of studies, being a fundamental field for the behavioral development in his area of educational interest, from that point of view he considers (Espinoza, 2021). One of the characteristics of PBL in the university setting that differentiates it from other learning approaches is cooperative work between peers in the search for alternative solutions to a professional problem. This problem must be considered the starting point that mobilizes the intellect of the apprentice, it must constitute a challenge for the learner by not being able to solve it with the knowledge he has. Previous knowledge can facilitate the understanding of the situation you are facing and draw up the strategies to achieve the proposed objective, but it requires an intellectual effort to obtain the necessary knowledge that will allow you to solve it. These characteristics of problem-based learning correspond to the principles on which this type of learning is based.

\section{Role of the tutor}

The teacher is key to facilitating self-directed learning. Branda (2009), argues that, in work in small groups, particularly in the study of interdisciplinary problems, the role of the teacher is fundamentally that of facilitator of student learning. It is necessary to ensure that students are clear about the role of the tutor or facilitator: to stimulate debate. The facilitating tutors are not the sources of information about the problem, not even when they know some aspects of the problem. The facilitating tutor does not teach in the conventional sense of the word but facilitates the learning process through questions that are intended to provoke thought and debate among students. It is very important to mention that the PBL's main role is for the teacher to facilitate the teaching-learning process of small or large groups so that the teacher raises problem situations, which leads to a series of conceptual content instructions to students, this allows you to create reflective thoughts within the classroom, thus leading to self-prepared learning in different disciplines that are presented.

The authors Pérez et al., (2020), state that the teacher presents the students with a problem situation or also known as scenario planning, previously selected or elaborated to favor certain skills in the student. The educator is the guide and facilitator of knowledge, who generates several questions for students so that they can answer or solve their environment according to the scenario. It should also be considered that the tutor not only imparts knowledge of the subject area of his specialty but also must master different strategies, methodologies, and techniques of group work, which develop the competencies of multiple intelligences that obtains each one so that the effectiveness of the work carried out and promotes the interest in learning starting from the study problem.

\section{Role of the student}

Under the guidance of a tutor, students should take responsibility for their learning, identifying what they need to know to better understand and manage the problem they are working on, and determining where to get the necessary information (books, magazines, teachers, internet, etc.) (Lozano, 2021). The faculty professors are consultants to the students, allowing each student to personalize their learning, concentrating on areas of limited knowledge, or understanding and pursuing their areas of interest.

Currently, education the main author of the educational process is the learner who learns under the guidance of the tutor, in autonomous, disciplinary preparation, thinking responsibly and authentically of the

Alava, J. B. C., Vera, L. E. A., Tipán, V. F., \& Pinargote, G. V. L. (2021). Problem-based learning as a methodological strategy in the teaching-learning process. International Journal of Social Sciences and Humanities, 5(3), 232-242. https://doi.org/10.53730/ijssh.v5n3.2028 
facts that arise in daily life (Calderhead, 1989; Evans, 2008). The student must work responsibly and know the ABP (Fernández \& Fonseca, 2016). A responsible integration around the group, as well as an enthusiastic attitude in solving the problem. Activities that can be developed with the PBL are shown.

a) Contribution of information to the group discussion. The above provides them with a detailed and specific understanding of all the concepts involved in addressing the problem.

b) Search for the information they consider necessary to understand and solve the problem; These forces them to put analysis and synthesis skills into practice.

c) Research (the library, electronic media, university teachers, or the group's colleagues)

d) Development of skills for analysis and synthesis of information, and a critical view of the information obtained.

e) Commitment to identifying the basic mechanisms that can explain each important aspect of each problem.

f) Stimulate within the group the use of collaborative skills and experiences of all members, pointing out the need for information and communication problems.

g) Openness to learning from others, commitment to sharing knowledge, experience, or skills to analyze and synthesize information.

h) Identify learning priorities, bearing in mind that the main task of each problem is to achieve certain learning objectives and not only to reach the diagnosis and solution of the problem.

i) During the work sessions, guide the participants towards the discussion of the learning objectives and do not divert the interventions to other topics.

j) Opening to ask the questions that are necessary to clarify the information and cover the proposed objectives for the session.

k) Share information during the sessions, stimulating the communication and participation of the other members of the group. Working in a group is more empathetic since it helps to have cooperative learning with others, which in turn motivates to share ideas to structure them and translate them into a study content.

\section{Steps that define Problem-Based Learning}

The development of the PBL Learning process is defined with 8 fundamental steps in the development of the cognitive process, for which Morales \& Landa (2004), states that the following are displayed:

a) Read and analyze the problem scenario: This is intended for the student to verify their understanding of the scenario by discussing it within their work team.

b) Brainstorm: Students usually have theories or hypotheses about the causes of the problem; or ideas of how to solve it.

c) Make a list of what is known: A list should be made of everything the team knows about the problem or situation.

d) Make a list of what is unknown: A list should be made of everything that the team believes should be known to solve the problem. There are many different types of questions that may be appropriate; some may relate to concepts or principles that must be studied to resolve the situation.

e) Make a list of what needs to be done to solve the problem: Plan research strategies. As a group, the students should draw up a list of the actions to be carried out.

f) Define the problem: Consists of a couple of statements that clearly explain what the team wants to solve, produce, answer, prove, or demonstrate.

g) Obtain information: The team will locate, collect, organize, analyze, and interpret information from various sources.

\section{Present results}

The team will present a report or make a presentation in which recommendations, predictions, inferences, or whatever is convenient to the solution of the problem are shown. All the steps are strategies that appear as self-directed learning in knowledge, to lead to the resolution of problems established in a certain topic. After 
having applied the survey to 15 teachers from the Veintitrés de Octubre Educational Unit, from the city of Manta in the Montecristi canton to inquire about Problem-Based Learning, the following results were obtained as shown in figure 2 .

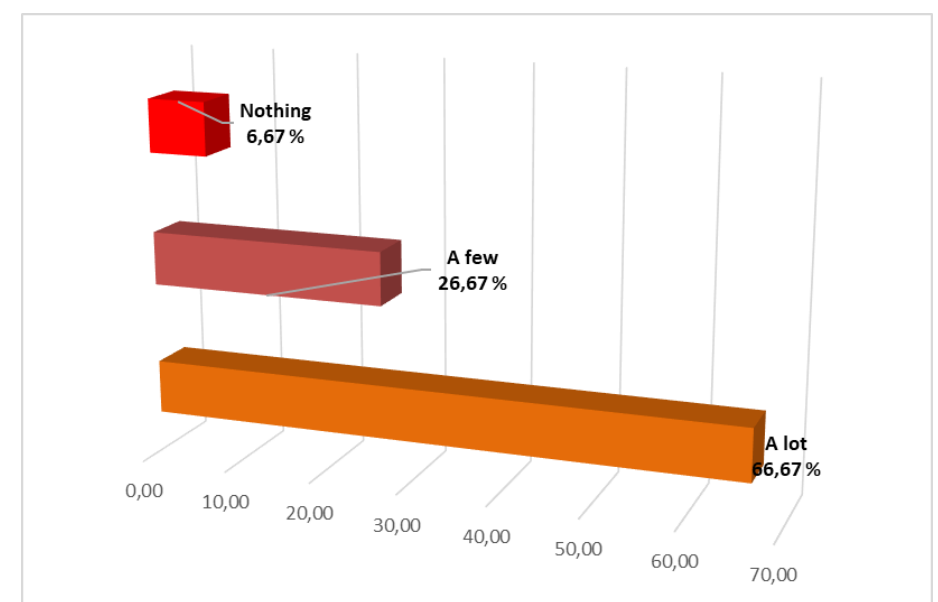

Figure 2. Problem-Based Learning as a methodological strategy Source: surveyed teachers of the Educational Unit

As seen in figure 2, 66.67\% of surveyed teachers stated that they know a lot about problem-based learning and that it is a teaching methodological innovation that allows the student to solve a problem through the available resources, while $26.67 \%$ indicated that they know little about this methodology because they do not implement it within their classes and $6.67 \%$ indicate that they do not know anything about this teaching method. In agreement with Muñoz-Repiso \& Gómez-Pablos (2017), they state that projects are a different way of working in the classroom, which encourages students to investigate, based on questions that are considered useful and important and that, in some cases, have arisen from themselves.

During the development of a project, students explore and discover interests, ask questions, organize their work, seek information from various sources, share their conceptions and compare them with new information, enrich or transform them, communicate results, make proposals. Figure 3 shows one of the queries made related to whether this methodology improves learning in the classroom.

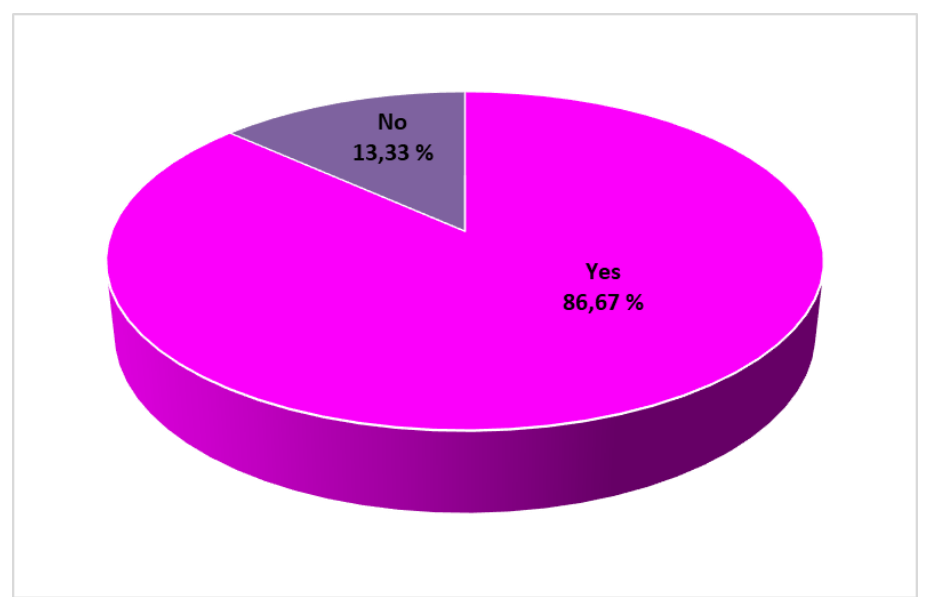

Figure 3. Problem-Based learning improves learning in the classroom Source: Teachers surveyed from the educational unit

The results obtained in figure $3,86.67 \%$ show that this methodology does improve learning in the classroom because it allows the student to empower themselves knowledge and makes them protagonists of their

Alava, J. B. C., Vera, L. E. A., Tipán, V. F., \& Pinargote, G. V. L. (2021). Problem-based learning as a methodological strategy in the teaching-learning process. International Journal of Social Sciences and Humanities, 5(3), 232-242. https://doi.org/10.53730/ijssh.v5n3.2028 
cognitive process, giving answers to real life problems, while $13.33 \%$ indicate that they do not consider that this methodology improves learning in all basic years, the same that cannot be applied to lower grade students because mastery of technology and leadership are needed when executing them. These results are supported by Lárez \& Jiménez (2019), who state that the ABP represents by its nature and characteristics a methodology with a high potential to promote the development of cognitive skills of particular interest to students. Among them can be mentioned: critical thinking, autonomy in learning, the construction of meaningful learning, the development of divergent thinking, self-discipline, creativity, responsibility, cooperative and collaborative work, search, organization, critical analysis, and use of information, figure 4 shows the results obtained when it is consulted if the student becomes a researcher with the use of this methodology by the teacher.

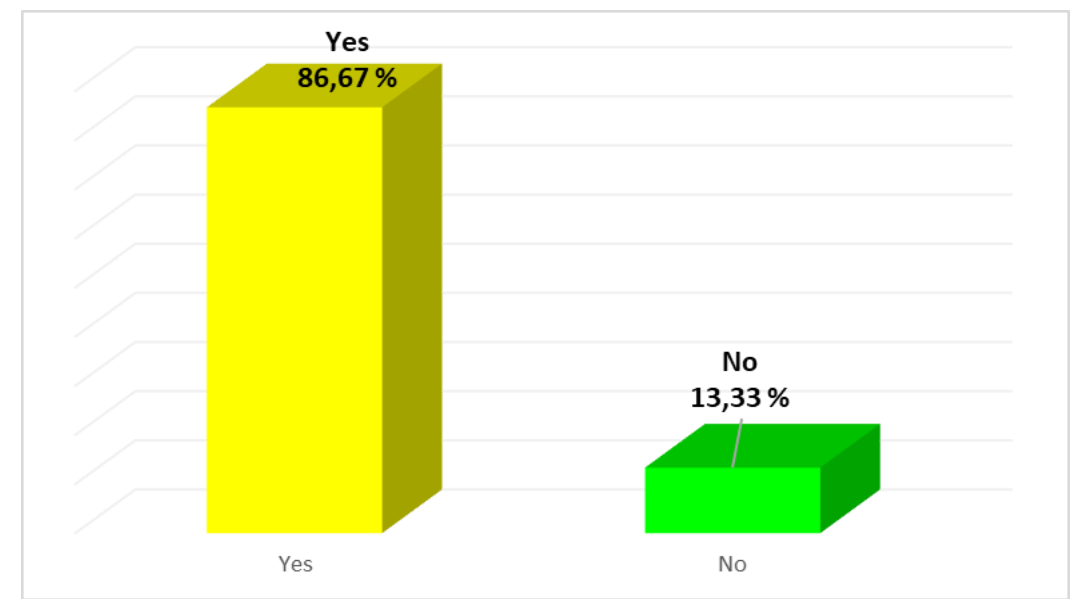

Figure 4. The ABP turns the student into an innovative and investigative entity Source: Teachers surveyed from the educational unit

As noted in the results of $86.67 \%$ indicate that the student does become an innovative and investigative entity at the time of actively getting involved in their learning because they learn to give possible answers to some problem in real life and based on this, they create a solution and $13.33 \%$ say that they do not because correct guidance is needed from the teacher. According to Pérez \& Chamizo (2011), they indicate that the methodology is an innovative educational proposal, characterized by promoting meaningful learning and helping to develop a series of skills and competencies that are essential for the intellectual growth of any person. In figure 5, it can be seen how teachers consider the PBL.

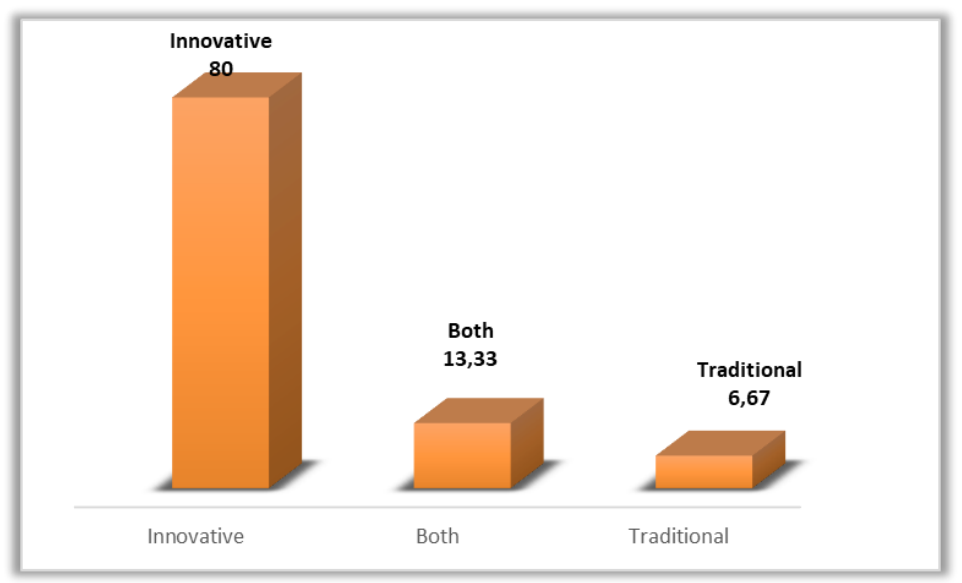

Figure 5. PBL as an innovative strategy

Source: Teachers surveyed from the educational unit 
As shown in figure 5, 80\% indicate that Problem-Based Learning is an active and innovative technology within the classroom because it allows promoting educational process more dynamically, making the student a researcher and work collaboratively, while $13.33 \%$ indicate that this method has combined both the traditional and the innovative and $6.67 \%$ indicate that the PBL is traditional since today there are new active methodologies such as the Universal Learning Design (DUA), the flipped classroom, among others that help the student to relate directly to the knowledge supported by their teacher. In agreement with Peralta \& Guamán (2020), those that indicate that the teaching and learning methodologies in Basic Education allow recommending active methodologies, characterized by being based on the constructivist theory that focuses the teaching-learning process in the student, giving it a leading role; promote active participation and cooperative work relationships; reject the memory process and pursue creativity and critical reflection; and have as a didactic-methodological resource the resolution of real problems. Figure 6 shows what was consulted regarding the contributions of the $\mathrm{ABP}$ in solving problems and acquiring knowledge.

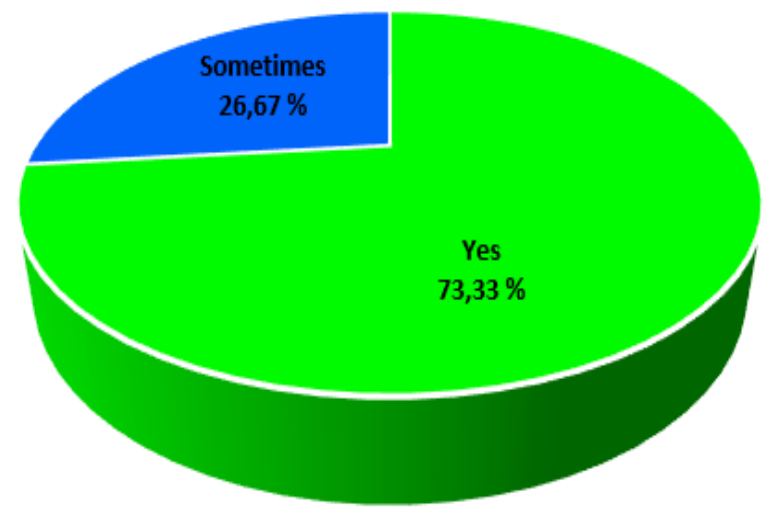

Figure 6. PBL as problem-solving and knowledge acquisition Source: Teachers surveyed from the educational unit

As shown in figure 6,$73 ; 33 \%$ of the teachers surveyed indicate that students do manage to solve problems and acquire new knowledge through the execution of problem-based projects, while $26.67 \%$ state that sometimes the learner manages to grasp the knowledge since on some occasions the lack of information and collaboration with each other makes it difficult for the problem to be solved in the best way. According to Colón \& Ortiz (2020), they indicate that the use of the ABP strategy to teach and learn, promotes in the student the investigation of raised situations, and motivates the interaction between the students and the educational material; between students, between students and the teacher, allowing the negotiation of meaning and the transfer of content to new situations. The teacher implements the PBL as a methodological strategy in the classroom and invites his students to create new learning resources, to go deeper into problems raised from their experiences, turning them into proactive entities for society.

\section{Conclusion}

The PBL as a methodological strategy in the teaching process creates in the student more complex and meaningful learning that provokes in him autonomy in his training and above all that allows relating the problems of the real world with their context, to search for effective way alternative solutions to improve your learning. Students develop abilities and skills from an investigation that fosters interest, makes it more critical, more analytical, leads them to learn, be investigative, to build their knowledge, especially defending their positions supported by scientific information, the important factor is to work cooperatively and collaboratively.

Alava, J. B. C., Vera, L. E. A., Tipán, V. F., \& Pinargote, G. V. L. (2021). Problem-based learning as a methodological strategy in the teaching-learning process. International Journal of Social Sciences and Humanities, 5(3), 232-242. https://doi.org/10.53730/ijssh.v5n3.2028 
Acknowledgments

The authors express their gratitude to the IJSSH team and collaborators, for the editorial boards, as well as for their valuable time, support, and advice on the present study. A special thanks to Dr. María Rodríguez Gámez for all her teachings and dedication to guiding us for this scientific work. 


\section{References}

Alkhasawneh, I. M., Mrayyan, M. T., Docherty, C., Alashram, S., \& Yousef, H. Y. (2008). Problem-based learning (PBL): assessing students' learning preferences using VARK. Nurse education today, 28(5), 572-579. https://doi.org/10.1016/j.nedt.2007.09.012

Berkhof, M., van Rijssen, H. J., Schellart, A. J., Anema, J. R., \& van der Beek, A. J. (2011). Effective training strategies for teaching communication skills to physicians: an overview of systematic reviews. Patient education and counseling, 84(2), 152-162. https://doi.org/10.1016/j.pec.2010.06.010

Branda, L. (2009). Problem-based learning. 21.

Calderhead, J. (1989). Reflective teaching and teacher education. Teaching and teacher education, 5(1), 43-51. https://doi.org/10.1016/0742-051X(89)90018-8

Celik, P., Onder, F., \& Silay, I. (2011). The effects of problem-based learning on the students' success in physics $\begin{array}{llr}\text { course. Procedia-Social and } & \text { Behavioral 656-660. }\end{array}$ https://doi.org/10.1016/j.sbspro.2011.11.124

Coila, M., Pacca, S., \& Mancha, E. (2019). Problem-Based Learning as a strategy for the development of competencies in secondary school students. 10(2).

Colón, L., \& Ortiz, J. (2020). Effect of the Use of the Problem-Based Learning Teaching Strategy (PBL) in the Development of Comprehension and Analysis Skills of Descriptive Statistics. Ibero-American Journal of Educational Evaluation, 13(1), 210.

Dewi, K. T. (2018). Developing assessment instrument based curriculum 2013 for teaching micro teaching in English education department of Undiksha. International Journal of Social Sciences and Humanities, 2(3), 95-106. https://doi.org/10.29332/ijssh.v2n3.205

Eisner, E. W. (2002). From episteme to phronesis to artistry in the study and improvement of teaching. Teaching and teacher education,18(4), 375-385. https://doi.org/10.1016/S0742051X(02)00004-5

Espinoza, E. (2021). Problem-based learning, a challenge to higher education. 17(80).

Evans, C. (2008). The effectiveness of m-learning in the form of podcast revision lectures in higher education. Computers \& education, 50(2), 491-498. https://doi.org/10.1016/j.compedu.2007.09.016

Fernandez, L., \& Fonseca, S. (2016). Problem-based learning. 20(9).

González, A. E., \& del Valle López, Á. (2008). Problem-based learning: A methodological proposal in higher education (Vol. 18). Narcea Editions.

Gorghiu, G., Drăghicescu, L. M., Cristea, S., Petrescu, A. M., \& Gorghiu, L. M. (2015). Problem-based learning-an efficient learning strategy in the science lessons context. Procedia-social and behavioral sciences, 191, 18651870. https://doi.org/10.1016/j.sbspro.2015.04.570

Hallgren, M., \& Olhager, J. (2006). Quantification in manufacturing strategy: A methodology and illustration. International Journal of Production Economics, 104(1), 113-124. https://doi.org/10.1016/j.ijpe.2005.09.004

Hedegaard, M. (2014). The significance of demands and motives across practices in children's learning and development: An analysis of learning in home and school. Learning, culture and social interaction, 3(3), 188-194. https://doi.org/10.1016/j.lcsi.2014.02.008

Lárez, J., \& Jiménez, M. (2019). Problem-Based Learning (PBL) as a strategy to promote Environmental Education training in university students: an approach from Didactics. Revista de Investigación, 43(98), 63.

Lozano, E. (2021). Didactic deployment of Problem-Based Learning by the tutor in Veterinary Medicine and Animal Husbandry modules. (33).

Morales, P., \& Landa, V. (2004). Problem-based learning. 13, 154.

Muñoz-Repiso, AGV, \& Gómez-Pablos, VB (2017). Project Based Learning (PBL): evaluation from the perspective of Primary Education students. Journal of Educational Research , 35(1), 113-131.

Peralta, D., \& Guamán, V. (2020). Active Methodologies For The Teaching And Learning Of Social Studies. Sociedad \& Tecnología, 3(2), 8.

Pérez Campillo, Y., \& Chamizo Guerrero, J. A. (2011). Museums: an instrument for Problem Based Learning (PBL). Eureka Magazine on Science Teaching and Outreach, 8(3).

Perez, V., Hernandez, F., \& Paniagua, S. (2020). Problem Based Learning (PBL).

Alava, J. B. C., Vera, L. E. A., Tipán, V. F., \& Pinargote, G. V. L. (2021). Problem-based learning as a methodological strategy in the teaching-learning process. International Journal of Social Sciences and Humanities, 5(3), 232-242. https://doi.org/10.53730/ijssh.v5n3.2028 
Rots, I., Aelterman, A., Vlerick, P., \& Vermeulen, K. (2007). Teacher education, graduates' teaching commitment and entrance into the teaching profession. Teaching and Teacher education,23(5), 543-556. https://doi.org/10.1016/j.tate.2007.01.012

Seufert, T. (2003). Supporting coherence formation in learning from multiple representations. Learning and instruction, 13(2), 227-237. https://doi.org/10.1016/S0959-4752(02)00022-1

Vetchinova, M. N., \& Shishova, V. A. (2020). Culturological ideas of teaching a foreign language: concepts and theories (the end of 20th - at the beginning of the 21st century). International Journal of Social Sciences and Humanities, 4(2), 39-49. https://doi.org/10.29332/ijssh.v4n2.404

\section{Biography of Authors}

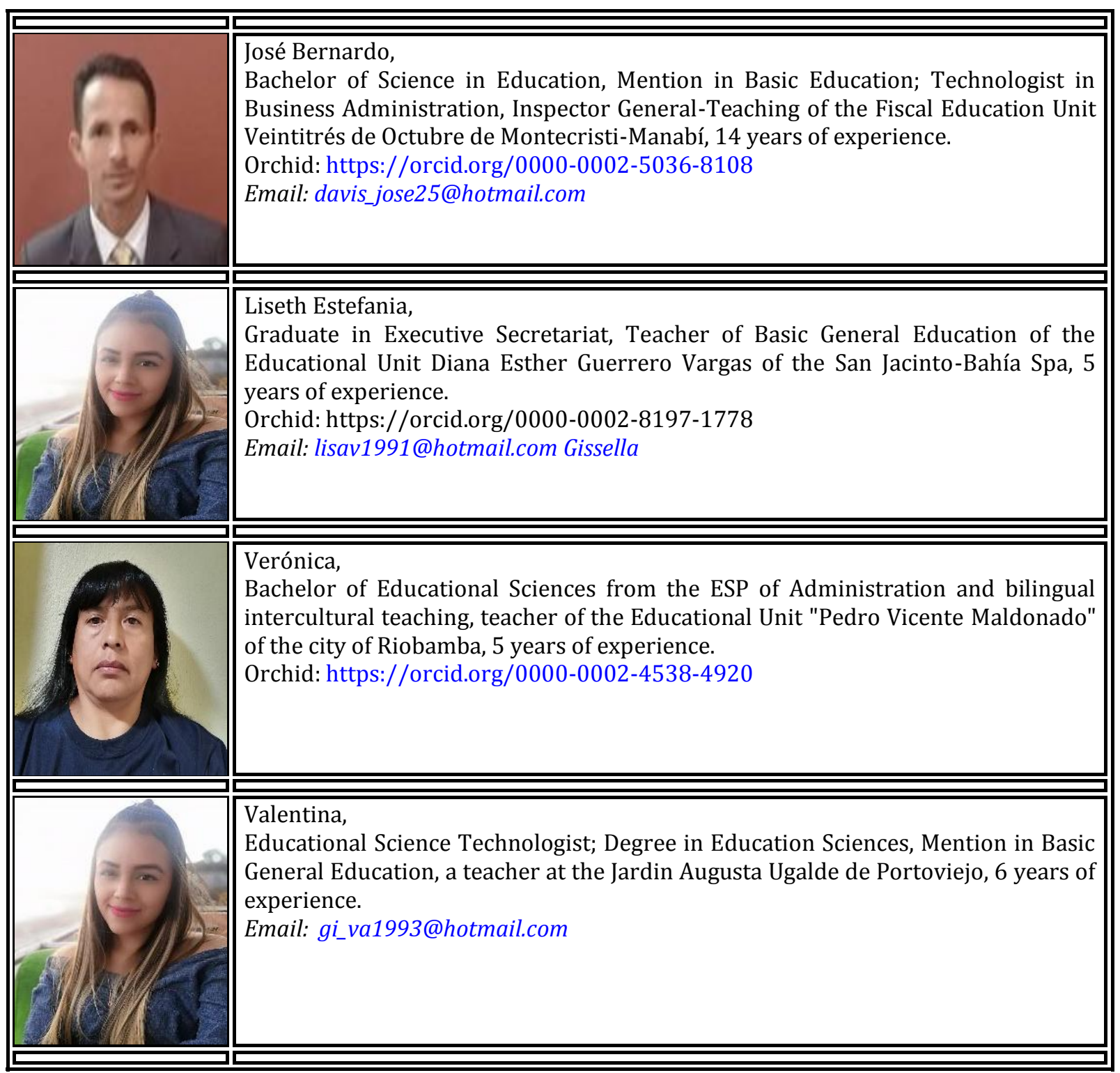

